\title{
Phenylacetic acid in human body fluids: high correlation between plasma and cerebrospinal fluid concentration values
}

\author{
M SANDLER,* CRJ RUTHVEN,* BL GOODWIN,* A LEES,† GM STERN† \\ From the Bernhard Baron Memorial Research Laboratories and Institute of Obstetrics and Gynaecology, \\ Queen Charlotte's Hospital,* and the Department of Neurology, University College Hospital, London†
}

SUMMARY In a group of six Parkinsonian patients and 13 "controls" with non-Parkinsonian neurological disease, there was a high correlation between both free and conjugated phenylacetic acid concentrations in plasma and cerebrospinal fluid taken at about the same time. This compound is the major metabolite of phenylethylamine, the production of which may be disturbed in a number of neuropsychiatric illnesses. Thus plasma measurements might be employed clinically to provide an estimate of central changes in phenylethylamine economy. A small but significantly higher proportion of conjugated phenylacetic acid was present in the plasma (but not cerebrospinal fluid) of Parkinsonians compared with controls.

Phenylacetic acid is the major metabolite of phenylethylamine, a "trace amine"1 which has become the focus of considerable clinical attention in recent years. This amine has been invoked as a possible aetiological agent in the pathogenesis of certain disease states, including depressive illness, ${ }^{2}$ schizophrenia $^{3}{ }^{3}$ migraine ${ }^{4}$ and aggressive psychopathy. ${ }^{5}$ Because phenylethylamine itself is normally present in body fluids in very low concentration requiring extremely sensitive methods for its estimation which, by their nature, are exacting and prone to interference, phenylacetic acid assay has become accepted as a guide to the production of its parent monoamine. Like phenylethylamine, unconjugated phenylacetic acid is a lipid-soluble relatively non-polar compound which might be expected to penetrate cell-membrane barriers with some facility. However, in the cat at least, the ${ }^{14} \mathrm{C}$-labelled acid is only able to cross the blood-brain barrier with difficulty. ${ }^{6}$ In man, this acid is excreted mainly as its glutamine conjugate ${ }^{7}$ which is much more polar and less lipid soluble than the free acid. Thus, little communication might have

Address for reprint requests: Professor Merton Sandler, Queen Charlotte's Maternity Hospital, Goldhawk Road, London W6 0XG, UK.

Received 13 November 1981

Accepted 9 December 1981 been expected between plasma and cerebrospinal (CSF) compartments.

With clinical interest being predominantly centred on neuropsychiatric illness, it has been tacitly assumed that information about central phenylethylamine economy might most usefully be obtained by determining phenylacetic acid levels in the CSF. ${ }^{8}{ }^{9}$ Where this has not been logistically feasible, however, plasma measurements have been performed. ${ }^{5}$ Although both approaches have yielded positive and distinctive findings, the relationship between the two groups of data remained unclear. We therefore decided to perform parailel studies on plasma and CSF samples drawn at about the same time to see whether we could identify any connexion between the two sets of values. Unexpectedly, we were able to identify a high degree of correlation not only between free phenylacetic acid values but also those of its glutamine conjugate.

\section{Methods}

Lumbar CSF and venous blood samples were drawn within 10 to $15 \mathrm{~min}$ of each other on in-patients at University College Hospital. The 13 "control" subjects (seven male, six female) were patients who had had CSF examinations performed as part of an investigation of peripheral neuropathy, radiculopathy or spinal cord 
disease. Six Parkinsonians (five male, one female) were recent admissions who had not begun levodopa therapy at the time the samples were collected. Blood was taken into lithium heparin tubes; plasma was separated immediately and stored at $-15^{\circ} \mathrm{C}$ to await analysis. CSF specimens were also stored at $-15^{\circ} \mathrm{C}$. Plasma and CSF concentrations of free and total (free + conjugated) phenylacetic acid were measured by gas chromatography-mass spectrometry using a selected ion monitoring procedure ${ }^{10}$ with slight modifications. $\left[D_{5}\right]$ phenylacetic acid was substituted for the $\left[D_{7}\right]$ isomer as internal standard in the estimation of free phenylacetic acid, and a mixture of $\left[D_{5}\right]$ phenylacetic acid plus $\left[D_{5}\right]$ phenylacetylglutamine (ratio $1: 2$ in CSF assay and 1:10 in plasma assay) was used, instead of [D;] phenylacetic acid, in the estimation of the total acid.

\section{Results}

Mean ( \pm SD) concentrations of free, conjugated and total phenylacetic acid in Parkinsonian and control plasma and CSF are shown in table 1. In both groups there were highly significant correlations between plasma and CSF concentrations of free, conjugated and total phenylacetic acid respectively. There was a small but significantly higher proportion of plasma (but not CSF) conjugated phenylacetic acid in Parkinsonians compared with controls (table 2).

\section{Discussion}

Although plasma concentrations of free acid were at least five times higher than those of CSF and the plasma levels of conjugated phenylacetic acid exceeded those of CSF at least twelve-fold, CSF values in an individual changed sensitively in direct proportion to those of the corresponding plasma. It may thus be inferred that, had Sandler et al measured plasma phenylacetic acid concentrations in their depressive $^{8}$ or schizophrenic $^{9}$ series, they would respectively have been decreased or increased, in proportion to the CSF values obtained. Had it, conversely, been practicable to acquire CSF samples from the aggressive psychopaths ${ }^{5}$ they described, we may suppose that they would have followed the raised plasma values observed in these subjects.

Despite the general consensus that phenylacetic acid production mirrors that of endogenous phenylethylamine, findings have begun to emerge making a reassessment of this view timely: germ-free rats excrete only about one quarter as much total phenylacetic acid as conventional controls, ${ }^{11}$ suggesting a sizeable contribution from the gut flora. However, the proportion of phenylacetic acid provided by gut flora (if these data can be extrapolated to man) may derive from some route of degradation different from that initiated by phenylalanine decarboxylation to phenylethylamine. Although the output of the latter is increased substantially in man following complete and irreversible inhibition of the phenylethylamine-preferring monoamine oxidase B by deprenyl, ${ }^{12}$ the total is still only a

Table 1 Showing plasma and cerebrospinal fluid (CSF) concentrations of free and conjugated phenylacetic acid in Parkinsonian and control subjects

\begin{tabular}{|c|c|c|c|c|c|c|c|}
\hline & & \multicolumn{3}{|c|}{ Control subiects $(n=13)$} & \multicolumn{3}{|c|}{ Parkinsonians $(n=6)$} \\
\hline & & Plasma & & $C S F$ & Plasma & & $C S F$ \\
\hline $\begin{array}{l}\text { Free phenylacetic } \\
\text { acid }(\mathrm{ng} / \mathrm{ml})\end{array}$ & $\begin{array}{l}\text { Mean } \pm \mathrm{SD} \\
\mathrm{R} \\
p\end{array}$ & $161 \cdot 8 \pm 80 \cdot 3$ & $\begin{array}{r}0.834 \\
<0.001\end{array}$ & $31 \cdot 6 \pm 23 \cdot 6$ & $105 \cdot 7$ - $84 \cdot 5$ & $\begin{array}{l}0.924 \\
<0.01\end{array}$ & $25 \cdot 6 \pm 15$ \\
\hline $\begin{array}{l}\text { Conj phenylacetic } \\
\text { acid }(\mathrm{ng} / \mathrm{ml})\end{array}$ & $\begin{array}{l}\text { Mean } \pm \mathrm{SD} \\
\mathrm{R} \\
p\end{array}$ & $412 \cdot 5=247 \cdot 9$ & $\begin{array}{r}0.900 \\
<0.001\end{array}$ & $29 \cdot 7 \pm 14 \cdot 3$ & $424 \cdot 5 \pm 339 \cdot 3$ & $\begin{array}{l}0.922 \\
<0.01\end{array}$ & $20 \cdot 2 \pm 6 \cdot 6$ \\
\hline $\begin{array}{l}\text { Total phenylacetic } \\
\text { acid (ng/ml) }\end{array}$ & $\begin{array}{l}\text { Mean } \pm \mathrm{SD} \\
\mathbf{R} \\
p\end{array}$ & $574.3=316.9$ & $\begin{array}{r}0.962 \\
<0.001\end{array}$ & $61 \cdot 3: 36 \cdot 3$ & $530 \cdot 2 \div 419 \cdot 7$ & $\begin{aligned} & 0.970 \\
< & 0.01\end{aligned}$ & $45 \cdot 8 \pm 21$ \\
\hline
\end{tabular}

Table 2 Comparing plasma and cerebrospinal fluid (CSF) concentration of free phenylacetic acid expressed as a percentage of concentration of conjugated and free plus conjugated (total) acid in Parkinsonians and control subjects

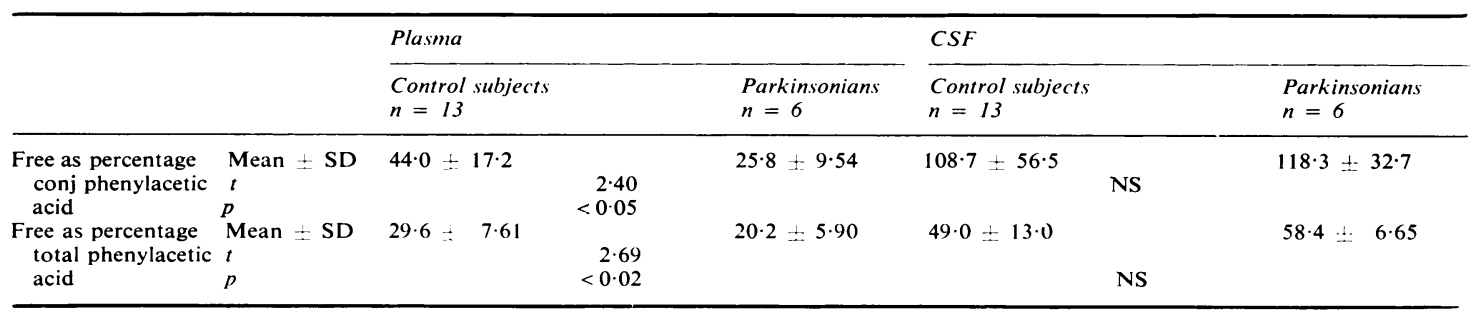


small fraction of the very large daily output of phenylacetic acid. ${ }^{7}$ Even though further information is required, however, before the full significance of changes in phenylacetic acid concentration in different clinical groups is clear, these findings can still be useful as state markers and employed accordingly, particularly for the purpose of defining subsets of particular diagnostic classifications. We should remember, too, that in clinical conditions associated with raised circulating concentrations of phenylacetic acid, 513 the literature provides us with ample reason for suspecting that the compound may, under certain circumstances, be toxic in its own right. ${ }^{14-19}$

There was one further finding of interest which emerged from this investigation. A small but significantly higher proportion of plasma (but not CSF) phenylacetic acid in Parkinsonians compared with controls was present in conjugated form, thus providing yet another biochemical change to add to the list of systemic (as opposed to central) deficits of this disease. Whilst its significance remains unclear, it is reminiscent of an earlier finding of ours in Parkinson's disease ${ }^{20}$ where we detected an increased basal urinary output of the (sulphate) conjugate of tyramine, another trace amine closely related to phenylethylamine. A more systematic study of conjugation mechanisms in general in this disease state might provide useful information.

\section{References}

1 Usdin E, Sandler M, eds. Trace Amines and the Brain. New York: Dekker, 1976.

${ }^{2}$ Fischer E. The phenethylamine hypothesis of thymic homeostasis. Biol Psychiatry 1975;10:667-73.

${ }^{3}$ Sandler M, Reynolds GP. Does phenylethylamine cause schizophrenia? Lancet 1976; ;:70-1.

${ }^{4}$ Sandler M, Youdim MBH, Hanington E. A phenylethylamine oxidising defect in migraine. Nature 1974;250:335-7.

${ }^{5}$ Sandler M, Ruthven CRJ, Goodwin BL, Field H, Matthews R. Phenylethylamine overproduction in aggressive psychopaths. Lancet 1978;ii:1269-70.

6 Pedemonte WA, Mosnaim AD, Bulat M. Penetration of phenylacetic acid across the blood-cerebrospinal fluid barrier. Res Commun Chem Pathol Pharmacol 1976;14:111-6.

7 Goodwin BL, Ruthven CRJ, Sandler M. Gas chroma- tographic assay of phenylacetic acid in biological fluids. Clin Chim Acta 1975;62:443-6.

${ }^{8}$ Sandler M, Ruthven CRJ, Goodwin BL, Coppen A. Decreased cerebrospinal fluid concentration of free phenylacetic acid in depressive illness. Clin Chim Acta 1979;93:169-71.

${ }^{9}$ Sandler M, Ruthven CRJ, Goodwin BL, et al. Raised cerebrospinal fluid phenylacetic acid concentration: preliminary support for the phenylethylamine hypothesis of schizophrenia? Commun Psychopharmacol 1978;2:199-202.

${ }^{10}$ Fellows LE, King GS, Pettit BR, Goodwin BL, Ruthven CRJ, Sandler $M$. Phenylacetic acid in human cerebrospinal fluid and plasma: selected ion monitoring assay. Biomed Mass Spectrom 1978;5: 508-11.

11 Sandler M, Bonham Carter S, Goodwin BL, Ruthven CRJ. Trace amine metabolism in man. In: Usdin E, Sandler M, eds. Trace Amines and the Brain. New York: Dekker, 1976:233-81.

${ }^{12}$ Elsworth JD, Glover V, Reynolds GP, Sandler M, Lees AJ, Phuapradit P, Shaw KM, Stern GM, Kumar P. Deprenyl administration in man: a selective monoamine oxidase B inhibitor without the "cheese effect". Psychopharmacology 1978;57:33-8.

13 Woolf LI. Excretion of conjugated phenylacetic acid in phenylketonuria. Biochem J 1951;49:ix-x.

${ }^{14}$ Sherwin CP, Woolf M, Woolf W. Maximum production of glutamine by the human body as measured by the output of phenylacetylglutamine. $J$ Biol Chem 1919;37:113-9.

${ }^{15}$ Sherwin CP, Kennard KS. Toxicity of phenylacetic acid. J Biol Chem 1919;40:259-64.

${ }^{16}$ Davison AN, Sandler M. Inhibition of 5-hydroxytryptophan decarboxylase by phenylalanine metabolites. Nature 1958;181:186.

17 Loo YH, Miller KA, Nowlin J, Horning MG. Identification of metabolites of phenylacetic acid in rat brain by plasma desorption mass spectrometry. Life Sci 1980;26:657-63.

${ }^{18}$ Fulton TR, Triano T, Rabe A, Loo YH. Phenylacetate and the enduring behavioral deficit in experimental phenylketonuria. Life Sci 1980;27:1271-81.

${ }^{19}$ Loo YH, Fulton T, Miller K, Wisniewski HM. Phenylacetate and brain dysfunction in experimental phenylketonuria: synaptic development. Life Sci 1980;27:1283-90.

${ }^{20}$ Bonham Carter SM, Youdim MBH, Sandler M, Hunter KR, Stern GM. Enhanced tyramine conjugation in Parkinson's disease. Clin Chim Acta 1974; 51 :327-9. 